\title{
The BlackBerry Veil: mobile use and privacy practices by young female Saudis
}

Blog Editor

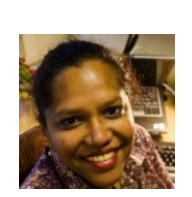

Privacy concerns in the digital economy are increasingly a global matter. The possible revival of the Communications Data Bill in the UK amidst fears over the vulnerability of the nation to terrorism highlights the topicality of this piece and the potential risks associated to ceding individual-to-government privacy for the sake of national security. In this post, Sunila Lobo presents the summary of an award winning paper coauthored with LSE Tech Silvia Elaluf-Calderwood, which suggests that Saudi Arabian female youth share similarities with youth around the world in their use of mobile phones, but negotiate privacy in a unique way.

Therefore, universal notions of privacy are challenged.

Set in the context of Saudi Arabia (population about 26 million as of July 2010; including more than 5 million foreigners), the dominant Arab nation in the Middle-east, the research is of particular interest due to the importance of mobile media for communication in this restrictive society and the sensitive nature of the context for conducting in situ research. In addition, most reports and studies of this region address the market and operator level rather than individual consumer-level concerns.

The telecommunications market in Saudi Arabia was liberalised in 2007 with Mobily, Zain and Saudi Telecom (the incumbent) the three licensed mobile service providers. The entry of Zain into the market in August 2008 generated higher levels of service competition and lower prices. The entry of an alternative fixed line operator, GO Telecom (used to be called Etihad Atheeb), further intensified competition. The trend since 2007 has been for slow fixed subscriber growth, with decline for the first time in Q3 2009, while there has been significant mobile subscriber growth over the same period. By Q4 2009, the totals were 45 million mobile subscribers and about 4.2 million fixed line subscribers (Communications and Information Technology Commission Report, Kingdom of Saudi Arabia; August 2010:p. 5). The mobile subscriber numbers are evidence that many people in Saudi Arabia have multiple mobile subscriptions, each for different purposes. Further, the availability of increasingly affordable broadband access has fuelled development of a digital economy comprising e-government, e-health (or mHealth), e-education, e-commerce and smart cities, with the largest investment in education. This is aligned with its vision of a knowledge-based economy, for its majority youthful population.

Given these factors, the telecommunications sector holds much promise but there are several factors including, trust and privacy that may pose a challenge. The study focuses on an under-researched group -highly educated group of young Saudi women-, its practices and motivations for mobile use, the particular domain of privacy and how this is negotiated in an Islamic social and cultural context thus investigates one of these concerns. It was conducted against the backdrop of the row about the Saudi government (UAE, India, Indonesia are others) insisting on RIM providing them the access to monitor email and messaging on BlackBerry by Saudi phone-subscribers.

The data showed that Saudi Arabian female youth share some similarities with youth around the world in their attachment to their mobile phones, and the use of content, camera and other applications but the way it is used to negotiate their various work, home and social domains vis-à-vis privacy, is unique. Variable user behaviour was found with regards to privacy, as their own individual view or societal view is driven not only by the capabilities of the technology, but how it is provided, particularly as there is indication of government monitoring of data content. There is a duality between individuals' perception of privacy; with regard to other individuals and with regard to their own government.

It also shows that of the two distinct levels of privacy, one has a greater influence than the other, on how Saudi Arabian women negotiate their lives in various domains within their society. In fact, the evidence would lead us to believe that one of these privacy levels (individual-government) has almost no influence on these women's consumption of mobile technology. These young women place importance on their individual-individual privacy space and are negotiating this privacy boundary among their peers, thereby defining in use, their own particular notion of privacy.

The telecommunications business model has to continue to evolve - other than enabling the provision of increasingly personalized services, issues of privacy need to be addressed to capture the value in this particularly lucrative mobile ecosystem. Commonly accepted or universal mobile privacy principles such as set out in 2011 by the GSMA will need to be reflected upon for applicability in different user contexts.

Note: The paper "The BlackBerry veil: mobile use and privacy practices by young female Saudis", Sunila Lobo and Silvia Elaluf-Calderwood, has received the Highly Commended Paper Award 2013 from the Emerald Literati Network Awards for Excellence 2013. 
Citation: Sunila Lobo, Silvia Elaluf-Calderwood, (2012) "The BlackBerry veil: mobile use and privacy practices by young female Saudis", Journal of Islamic Marketing, Vol. 3 Iss: 2, pp.190 - 206

This article gives the views of the author, and not the position of LSE Network Economy Blog nor of the London School of Economics.

\section{We welcome your comments! Please take a look at our comments policy}

\section{About the Author}

Dr Sunila Lobo is a Research Fellow at the Design Innovation Research Centre, University of Reading. Sunila has worked in Southeast-Asia, the UK and the Middle East. She has conducted research in the interdisciplinary technology/business space for more than a decade, including on changing business models with technological innovation. She has collaborated with global engineering and design consultancies, leading UK media and communications companies including BSkyB and Euskaltel and technology companies in Europe including Philips. She worked in the internet-based arm of a major telecommunications company in Malaysia (Maxis) during the euphoria of the dotcom boom; conducting portal strategy development for B2B and B2C services. Sunila's varied interests relating to how technology and society are mutually constituted has also led her to explore how new technologies are used for coordination and control and the related risks and privacy and data security issues.

This entry was posted in business models, convergence, cyberlaw, digital economy, mobile industry, policy, privacy, regulation, Research, Sunila Lobo, Telecoms and tagged mobile use, RIM, Saudi Arabia. Bookmark the permalink. 